\title{
Assessing Effects of Crop History and Soil Amendments on Yields of Subsequent Crops
}

\author{
Adrian C. Newton, David C. Guy \\ James Hutton Institute, Invergowrie, Dundee, UK \\ Email: adrian.newton@hutton.ac.uk
}

How to cite this paper: Newton, A.C. and Guy, D.C. (2020) Assessing Effects of Crop History and Soil Amendments on Yields of Subsequent Crops. Agricultural Sciences, 11, 514-527.

https://doi.org/10.4236/as.2020.115032

Received: April 25, 2020

Accepted: May 25, 2020

Published: May 28, 2020

Copyright $\odot 2020$ by author(s) and Scientific Research Publishing Inc. This work is licensed under the Creative Commons Attribution International License (CC BY 4.0).

http://creativecommons.org/licenses/by/4.0/

(c) (i) Open Access

\begin{abstract}
Three field trials were set up to measure the effect of previous crops or soil amendments on the yields of subsequent crops of cereals under a cool temperate maritime climate in arable crop land in the east of Scotland. Winter wheat and winter barley direct drilled into legume and cereal + legume stubble (pre-crop) gave substantial yield boost compared with other pre-crop cereals, but pre-crop effects of oats were similarly great. Restored rotation after continuous barley gave expected yield enhancement to subsequent winter and spring barley but not to subsequent wheat. Some diseases were reduced on restored rotation crops. Slurry effects on yield were generally small but beneficial and compost effects were greater. However, compost had effects on plant developmental speed and was difficult to compare directly with other treatments. NDRE measurements in the restored rotation and soil amendment trials indicated that yield gains were associated with improved crop health as indicated by leaf chlorophyll content. There were no clear cultivar interactions within crop type with treatments effects in any of these trials.
\end{abstract}

\section{Keywords}

Rotation, Yield, Soil Amendment, Legumes, Intercropping, Compost, Slurry

\section{Introduction}

The primary purposes of crop rotations are to maintain soil fertility and crop health although the mechanisms whereby this is achieved are often not fully understood [1]. It follows and is accepted that continuous cropping with the same crop species will lead to reduced yields and increased issues with pests and diseases. Nevertheless, the relatively high value and profitability of some cash crops such as winter wheat for milling across extensive areas, or more niche crops such as spring barley for malt distilling, dictate that they are sometimes grown more-or-less con- 
tinuously. The break crops that might be used to maintain or restore soil are often far less profitable. The issues can be compounded by investment in machinery and facilities for the cash crop and degradation of the resource and infrastructure to grow alternative crops.

Whether the true costs of continuous cropping with the same crop are generally known is debatable. Figures from Rothamsted comparing continuous cropping with a four-course rotation from 1852 to 1883 showed that barley was not affected whereas wheat, grazed turnips and faba beans yielded 19\%, 39\% and 55\% less respectively in continuous cropping [2]. However, later trials demonstrated considerable yield reduction of continuous barley, especially under the low nitrogen conditions used previously [3]. Dyke \& Slope [3] also showed correlated take-all ratings using root infection estimations that could explain the losses. However, Hornby \& Henden [4] showed that take-all decline generally establishes in continuous barley, thereby mitigating this effect in practice.

Degradation of soil health may lead to a greater demand for agronomic inputs such as fertilisers and pesticides as well as greater losses to the environment in terms of diffuse pollution, greenhouse gasses and carbon footprint, few of which are assessed or costed. Furthermore, few controlled comparisons are made with recognised good rotation practice as cropping patterns generally affect whole fields or farms and are therefore difficult to compare on any factorial basis. A further issue is that the agronomy advice and data on varieties is generally from good rotation managed trials that are not comparable with continuous cropping situations. Therefore, there is a need for an evaluation of which crops suffer by continuous cropping and by how much.

Break crops in a rotation can have very different effects on soil health, particularly when they are from different plant families from the predominant cash crop [5]. Legumes in particular can have a strong effect and the potential release of nitrogen to the following crop is often of considerable benefit [6]. Legumes are increasingly being exploited as components of intercrops too, so the effects on subsequent crops will reflect both the legume and other components [7]. However, the agronomic approaches used will affect how much of the nitrogen fixed by the legume is lost to the environment and how much becomes available at appropriate times to the subsequent crop. The effects of tillage could be particularly important to this effect [8].

Another approach to improving or maintaining soil health and thereby crop yield is by adding organic amendments that aim to improve the soil structure. These are commonly either animal waste such as slurry or compost such as that from domestic garden waste, and often result in yield gains in barley but effects are variable due to complex effects on soil quality [9] [10]. These should not only increase soil organic matter, but also affect the soil structure, chemistry and biology. In that these changes will affect soil function, not only might crop yields be affected, but also crop responses to both biotic and abiotic stress [11]. 


\section{Materials and Methods}

\subsection{Intercrop Pre-Crop Legacy Trial}

Pre-crops comprising a range of single species and intercrop plots, were sown in $100 \mathrm{~m} \times 3 \mathrm{~m}$ beds using an Amazone AD/P Super drill in combination with Amazone KG Power Harrow in September 2017 in Mains of Fowlis field, Balruddery farm in Angus, Scotland, UK (56 28 $\left.53.9^{\prime \prime} \mathrm{N} 3^{\circ} 06^{\prime} 33.2^{\prime \prime} \mathrm{W}\right)$. Monocultures were the following winter cultivars-pea: DSV E.F.B.33-P, faba bean: Tundra, rye: SU Performer, oat: Mascanni, barley: Sunningdale sown at 95, 50, 360, 360 and $200 \mathrm{seed} / \mathrm{m}^{2}$ respectively. Intercrop mixes of the above cultivars of pea + rye, pea + oat, pea + barley, bean + rye, bean + oat and bean + barley were sown at ratios of 30:70 legume:cereal at their respective sowing rates. The field was treated with the herbicide Glyphosate at the recommended rate prior to sowing but no other herbicides and no fungicides were used. Plots were sown in a randomised six replicate plot design. Plots were cut and allowed to wilt on $9^{\text {th }}$ July then removed by baling (and wrapping and weighing) on $10^{\text {th }}$ July.

In September 2018 the area of the above trial was treated with the herbicide Glyphosate at the recommended rate then winter wheat and winter barley cultivars and blends were direct drilled across the previous beds using a Trials Equipment custom-made plot drill using Hege technology feeding through two banks of four John Deere 750a direct drill disk coulters (TE direct plot drill) giving a row spacing of $16.5 \mathrm{~cm}$, which is the same as the standard commercial version of the John Deere 750a direct drill. The winter wheat cultivars were Leeds, Viscount, Moulton, LG Sundance, Elicit, Zulu, and equal proportion mixtures of Leeds + Viscount + Moulton, Sundance + Elicit + Zulu, and Leeds + Moulton + Sundance + Zulu all sown at $360 \mathrm{seed} / \mathrm{m}^{2}$. The winter barley cultivars and blends were KWS Tower, Surge, KWS Orwell, Funky, KWS Astaire, Sunningdale, Tower + Surge + Orwell, Funky + Astaire + Sunningdale, Tower + Surge + Funky + Sunningdale all sown at $360 \mathrm{seed} / \mathrm{m}^{2}$ apart from Sunningdale that was sown at $200 \mathrm{seed} / \mathrm{m}^{2}$. In April the following cultivars and blends of spring barley were sown in the same way: Concerto, KWS Sassy, RGT Planet, Laureate, KWS Irena, Propino, RGT Asteroid, LG Diablo, Concerto + KWS Sassy + Laureate, KWS Irena + Propino + LG Diablo, KWS Sassy + RGT Planet + RGT Asteroid + LG Diablo all sown at $360 \mathrm{seed} / \mathrm{m}^{2}$. Normal agronomy and full rate fungicides were applied to each respective crop but the nitrogen rates were about half of the normal rates: 100, 90 and $70 \mathrm{~kg} / \mathrm{ha}$ for winter wheat, winter barley and spring barley respectively, so that crops were likely to be in a nitrogen-responsive range to ensure soil fertility differences were expressed. Plots were combined with a Wintersteiger Quantum plot combine and weights adjusted for moisture were taken from the combine's onboard outputs.

\subsection{Rotation Restoration Trial}

The pre-crop area for investigating the effects of continuous barley was a field 
area measuring $100 \mathrm{~m} \times 100 \mathrm{~m}$ sown with either a single cultivar of winter barley or with plots of either winter barley or spring barley using standard crop or trial agronomy from September 2001 until September 2016 in Lab field, Mylnefield in Fife and Kinross, Scotland, UK (56 27'19.5"N 304'08.1"W). In April 2017 three areas measuring $100 \mathrm{~m} \times 15 \mathrm{~m}$ were then sown with spring barley again, cultivar Concerto, and another three areas of the same dimensions were sown with oilseed rape, cultivar Tamarin (Figure 1). These were managed with standard agronomy for the respective crop and harvested as normal. In April 2018 the barley areas were again sown with spring barley cultivar Concerto but the oilseed rape areas were sown with faba beans, cultivar Boxer, again managed with standard practice and harvested as normal. A "restored rotation" treatment was thus established in the areas sown with oilseed rape then faba beans for comparison with a "continuous barley" treatment.

In September 2018 plots were direct drilled along the $100 \mathrm{~m}$ (north-south) dimension of all 6 plot areas, i.e. three replicates of "continuous barley" and three replicates of "restored rotation". The TE plot drill was used to sow $16 \times 6$ $\mathrm{m}$ plots in each bed, reduced to $4.8 \mathrm{~m}$ with plot definitions. In each area two beds of winter wheat and two beds of winter barley were sown with a guard bed on either side. The wheat plots comprised 16 different entries: Elicit, Zulu, KWS Jackal, Myriad, and the four equal proportion by seed number 3-component mixtures of these cultivars; Leeds, Viscount, Moulton, LG Sundance, and the four equal proportion by seed number 3-component mixtures of these cultivars. Each of these two series of monocultures and all their possible 3-component mixtures were randomised within half a bed ( 8 plots), and these alternated north and south half in the pair of beds. Winter barley plots were set up in the same way, the cultivars being Funky, KWS Astaire, Sunningdale and Belmont on one series and KWS Cresswell, KWS Tower, Surge and KWS Orwell in the second series together with their respective 3-component mixtures. In April 2019 three beds of spring barley and a guard bed were set up in the same way, the cultivars being Concerto, KWS Sassy, RGT Planet and Laureate in one series and KWS Irene, Propino, Olympus and LG Diablo in the second series together with their respective 3-component mixtures. These were sown in the same format but with a Hege 8-row plot drill following minimum tillage rather than direct drilling. All plots were sown at $360 \mathrm{seed} / \mathrm{m}^{2}$ apart from for Sunningdale which was 200 seed $/ \mathrm{m}^{2}$ and received standard trial agronomy, the total nitrogen being 180, 160 and $100 \mathrm{~kg} / \mathrm{ha}$ for winter wheat, winter barley and spring barley respectively), but no fungicides were used. Diseases were assessed on a 1 to 9 scale where 1 is no disease and 9 is $100 \%$ necrosis (HGCA, 2018). Winter cultivar plots were scanned with a Crop Circle RapidScan CS-45 to assess vegetation indices on four occasions during their growth and an Area Under the Vegetation Development Curve (AUVDC) was calculated. Plots were harvested with a Wintersteiger Quantum plot combine when ripe, dried to constant moisture and weighed. 


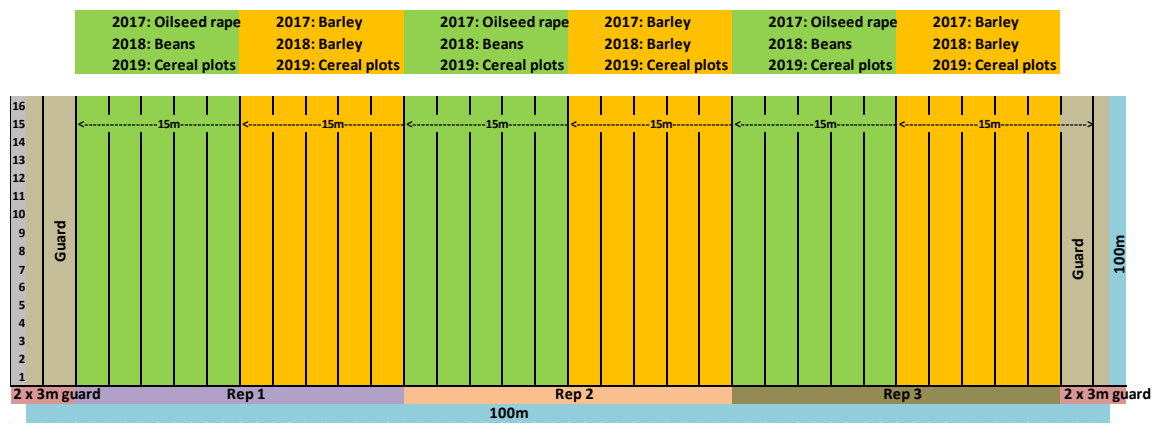

Figure 1. Schematic representation of the Lab Field rotation restoration trial showing the areas and years grown with barley, oilseed rape, beans and cereal plots. In 2017 and 2018 these were sown in the $5 \times 3 \mathrm{~m}$ drill strips shown $(15 \mathrm{~m})$. Beds of $16 \times 1.55 \mathrm{~m}$ wide plots of winter wheat and winter barley (autumn 2018) and spring barley (2019) were sown in the same areas and the same north-south direction.

\subsection{Soil Amendment Treatment and Trial Setup}

Three different soil amendment treatments were applied in Low Pilmore field, Mylnefield, Fife and Kinross, Scotland, UK (56 $\left.27^{\prime} 11.4^{\prime \prime} \mathrm{N} 3^{\circ} 04^{\prime} 50.5^{\prime \prime} \mathrm{W}\right)$, a field of sandy-loam soil from 2004 comprising "Discovery Compost", "slurry" and an unamended control (Figure 2). Discovery Compost was made from local garden waste composted to PAS100 standard and the slurry was from cattle sourced from local farms. Initially $50 \mathrm{t} / \mathrm{ha}$ compost was applied to all the compost treatment areas and $20 \mathrm{t} /$ ha slurry to the slurry areas in November 2004. In March 2005 and March 2006 the compost treatment had three levels, $200 \mathrm{t} / \mathrm{ha}, 100 \mathrm{t} / \mathrm{ha}$ and $0 \mathrm{t} / \mathrm{ha}$, and the slurry treatment similarly had levels of $40 \mathrm{t} / \mathrm{ha}, 20 \mathrm{t} / \mathrm{ha}$ and 0 t/ha. In March 2007, March 2008 and March 2009 the 0 t/ha treatments for compost and slurry were changed to $35 \mathrm{t} / \mathrm{ha}$ and $10 \mathrm{t} / \mathrm{ha}$ respectively. From March 2010 onwards, a single level of $35 \mathrm{t} / \mathrm{ha}$ and $10 \mathrm{t} / \mathrm{ha}$ were applied to all the compost and slurry treatment areas respectively. Every year the treated area and surrounding land was cultivated with minimum tillage and sown with a common contemporary commercial cultivar of spring barley under standard commercial crop agronomy. In 2017 the barley was sown very late ( $18^{\text {th }}$ May) and in 2018 on $30^{\text {th }}$ April to accommodate the plot trial (see below), but in all other years it was sown mid-April. The crop was combined with a commercial Claas Tucano 430 combine with a $6 \mathrm{~m}$ table and the onboard yield map data was used to determine the yield of each of the treatment areas.

In 2017 a spring barley plot trial was sown across the northern half the treatment area and in 2018 across the southern half, but all treatments and treatment levels were present in 3 replicates in each year (Figure 2). Eight spring barley cultivars were sown with the Hege plot drill, each bed comprising a single cultivar in a continuous sowing. Plots were then defined by removing a $1.5 \mathrm{~m}$ strip overlaying the interface between the soil amendment treatments and levels. The cultivars were: RGT Planet, KWS Irena, KWS Sassy, Concerto, Scholar, Laureate, Waggon and Fairing. All plots received standard trial agronomy $(110 \mathrm{~kg} / \mathrm{ha}$ nitrogen) including fungicide treatments where required and plots were harvested 
when ripe with a Wintersteiger Quantum plot combine, dried to constant moisture and weighed.

\subsection{Data Analysis}

The data were subject to Analysis of Variance (ANOVA) using Genstat $19^{\text {th }}$ edition (VSN International Ltd., Hemel Hempstead, UK), checking data for normal residuals. Disease scores were converted to percentage equivalents before analysis but it was not found to be necessary to transform these data. Contrasts were calculated to determine the significance differences between the pre-crop treatment group (A and $\mathrm{B}$ ) responses.

\section{Results}

\subsection{Intercrop Pre-Crop Legacy Effects on Yield}

For all three crop types there were highly significant $(\mathrm{p}<0.001)$ effects of the pre-crop on yield. Cultivar differences were highly significant for winter and spring barley $(\mathrm{p}<0.001)$ and $\mathrm{p}=0.013$ for winter wheat. There was no indication of any cultivar or cultivar mixture interaction with pre-crop treatment.

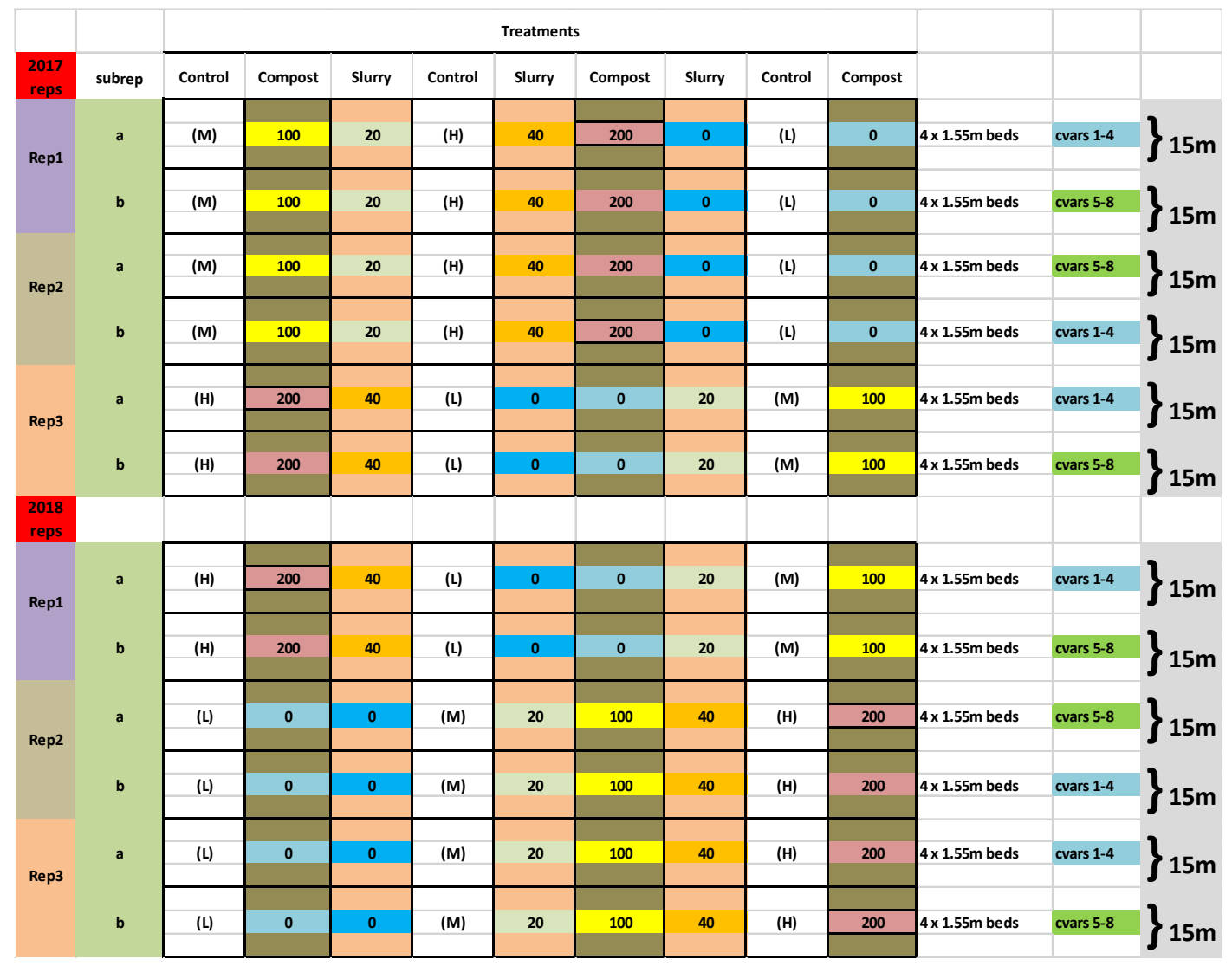

Figure 2. Schematic representation of the Low Pilmore treatment types, treatment levels and placement of plots of spring barley over these treatments in 2017 and 2018. Subrep groups of cultivars 1 - 4 (RGT Planet, KWS Irena, KWS Sassy and Concerto) and 5 - 8 (Scholar, Laureate, Waggon and Fairing) were randomised, each group being sown in the centre of the subrep equidistant from the next set. 
Plotting the pre-crop treatment means for each crop in order of the winter crop overall means, the pre-crop treatments form two distinct groups for winter wheat and winter barley, and to a lesser extent for spring barley also (Figure 3 ). The two groups were barley- and rye-dominated pre-crops (Group A) and pea-, bean- and oat-dominated pre-crops (Group B). For winter wheat the average yield increase for the bean, pea and oat monocultures as well as the oat with bean and oat with pea intercrops was about $30 \%$ more than the average of the barley- and rye-dominated treatments. For winter barley the difference was approximately $21 \%$ and for spring barley $10 \%$ and using contrasts, these differences were significant for all three crops (winter wheat and winter barley $\mathrm{p}<0.001$, spring barley $\mathrm{p}=0.002$ ) (Table 1 ). The three cereal crops clearly respond differently in terms of magnitude of response but follow similar trends. Although there were few trial entries that were mixtures rather than pure cultivars, there was no evidence that they behaved any differently from the mean of their respective monocultures.

The normalized difference red edge index (NDRE) was greater for winter wheat in the pea-, bean- and oat-dominated pre-crops compared with the other pre-crop group $(\mathrm{p}<0.001)$ but for winter barley there was no difference (Figure 4 ).

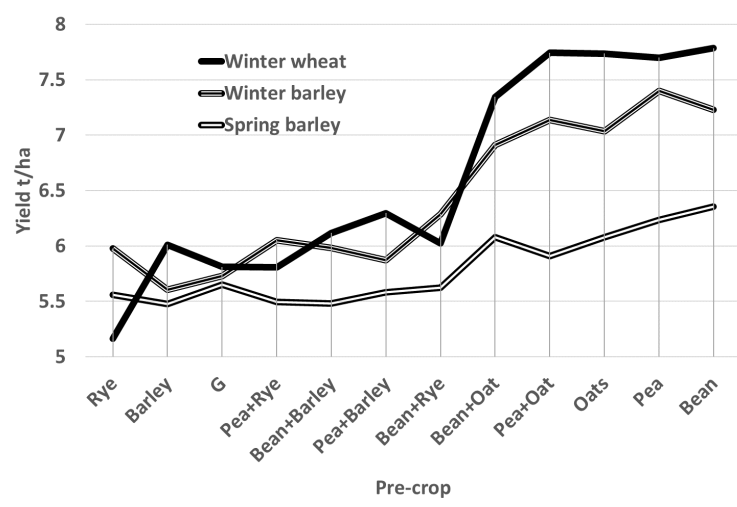

Figure 3. Effect of previous crop on subsequent winter wheat, winter barley crop and spring barley, ordered by the yield of the pre-crop treatment means. Pre-crop ${ }^{\star}$ crop l.s.d. $=0.219(\mathrm{WW}), 0.271(\mathrm{WB}), 0.198(\mathrm{SB})$.

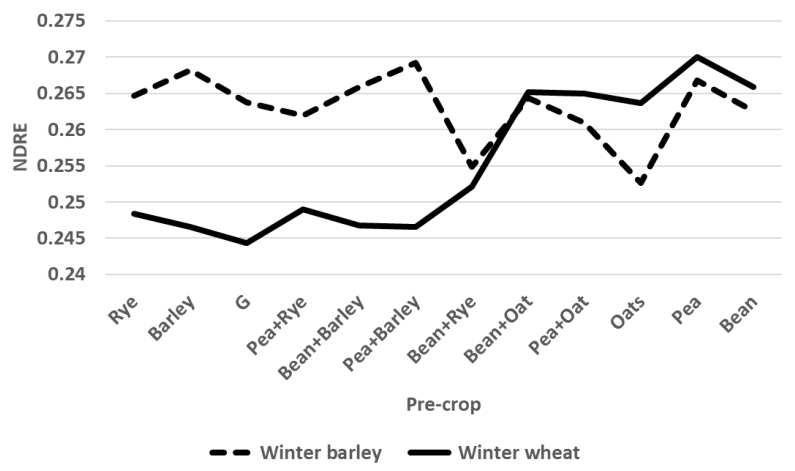

Figure 4. Effect of previous crop on subsequent winter wheat, winter barley crop ordered by the yield of the pre-crop treatment means on NDRE measured on 3rd June 2019. Pre-crop ${ }^{\star}$ crop 1.s.d. $=0.008$. 
Table 1. Comparison of barley- and rye-dominated pre-crops (Group A) with pea-, beanand oat-dominated pre-crops (Group B) for yield.

\begin{tabular}{llll}
\hline Crop & Group A & Group B & \% increase \\
\hline Winter barley & 5.93 & 7.14 & $21 \%$ \\
Winter wheat & 5.89 & 7.66 & $30 \%$ \\
Spring barley & 5.55 & 6.13 & $10 \%$ \\
\hline
\end{tabular}

\subsection{Rotation Restoration Effects on Yield and Disease}

There was a highly significant yield increase of about $19 \%$ and $26 \%$ in the yield of winter barley and spring barley on the restored rotation compared continuous barley ( $\mathrm{p}<0.001$; Figure 5), but for winter wheat there was no significant effect. There were no cultivar interactions with pre-crop, nor monocultures compared with mixtures overall.

Powdery mildew levels on winter wheat reached an average of around 2.5\% and wheat yellow rust reached an average of around $27 \%$ in mid-June. Winter barley had much higher levels of powdery mildew at $40 \%$ in mid-June but rhynchosporium levels only reached around $3 \%$. No significant disease was recorded on spring barley. There was a small but significant effect of pre-crop on powdery mildew levels on winter wheat and winter barley and rhynchosporium on winter barley, the restored rotation pre-crop having about $15 \%, 20 \%$ and $21 \%$ less respectively ( $p=0.003$ or less). There was no effect of pre-crop on yellow rust on wheat. There was a significant reduction of $33 \%$ in yellow rust on wheat in mixtures compared with monoculture means but no interaction with pre-crop and no other mixtures significantly changed disease levels compared with monocultures means.

The NDRE was used to calculate Area Under the NDRE curve and this was significantly different for crop * rotation effect $(\mathrm{p}<0.001)$ and the plotted values for winter wheat and winter barley crops on each treatment across time shows that it was generally greater for the restored rotation treatments for both crops (Figure 6).

\subsection{Soil Amendment Treatment Effects on Yield}

Yield measured on the whole area excluding the plot area in 2017 and 2018 varied significantly with year, amendment, amendment level and for all interactions $(\mathrm{p}<0.001)$. The general trends are most clearly seen in the plot of the mean treatment levels (Figure 7). Initially, particularly in the first three years, the compost treatment appeared most beneficial but subsequently the slurry appeared most beneficial and the compost least, although differences were apparently minimal in the two plot trial years. In 2016 the treatments converged although compost dropped away again in 2017. In both 2017 and 2018 the yields were substantially lower than normal but a small benefit of the organic matter in the two amendments did improve yield in 2018.

The plot trials in 2017 and 2018 showed significantly effects for year, amendment, amendment level and for year * amendment, year * cultivar and year * 
amendment $*$ level interactions $(\mathrm{p}<0.001)$. Year ${ }^{*}$ level and treatment ${ }^{*}$ level were showed more marginal effects $(\mathrm{p}=0.055$ and $\mathrm{p}=0.003)$.

In 2017 the plot trial showed significant cultivar and treatment differences ( $p$ $=0.014$ and $\mathrm{p}<0.001$ respectively) but no interactions apart from treatment and level of treatment $(\mathrm{p}<0.001)$. The size of the difference between the positive slurry response and negative compost response and the control, appeared to be negatively correlated with yield. This was most noticeable for lowest-yielding pair, KWS Irena and Concerto with the highest-yielding pair, KWS Sassy and RGT Planet. However, whilst comparing cultivar groups using contrasts indicated some support for such correlations in 2017, cultivars responded differently in 2018 so no reliable cultivar adaptation differences could be supported (Figure 8).

The NDRE measured on $13^{\text {th }}$ May in 2017 and $18^{\text {th }}$ June 2018 was greater on compost and least on the control treatments in both years $(\mathrm{p}<0.001$, Figure 9) which was confirmed by clear visual differences in growth stage particularly in the high level compost treatment areas observed in aerial images of the trial in 2017 (image not shown).

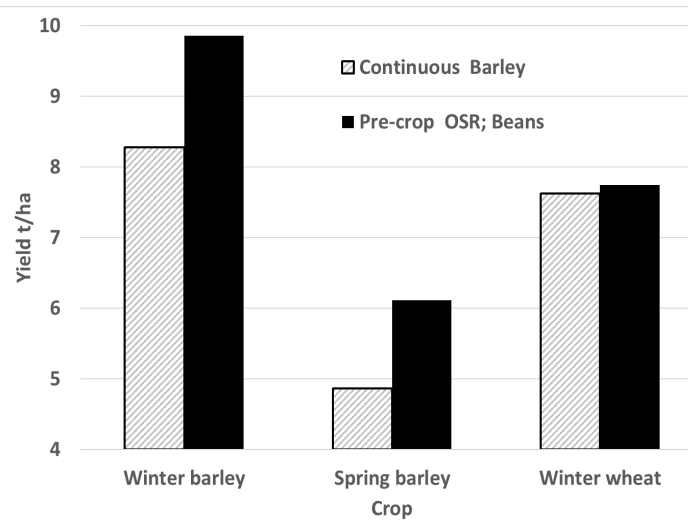

Figure 5. Effect of continuous barley or restored rotation on the yield of subsequent crops of cereals. Crop ${ }^{\star}$ pre-crop l.s.d. $=0.419$ (winter crops), 0.200 (spring barley).

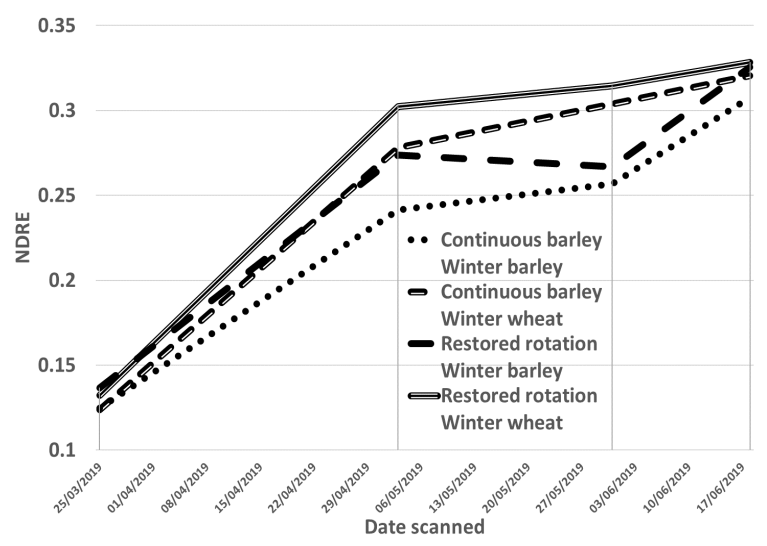

Figure 6. Effects continuous barley or restored rotation on the Normalised Difference Red Edge Index progress of subsequent crops of cereals. 


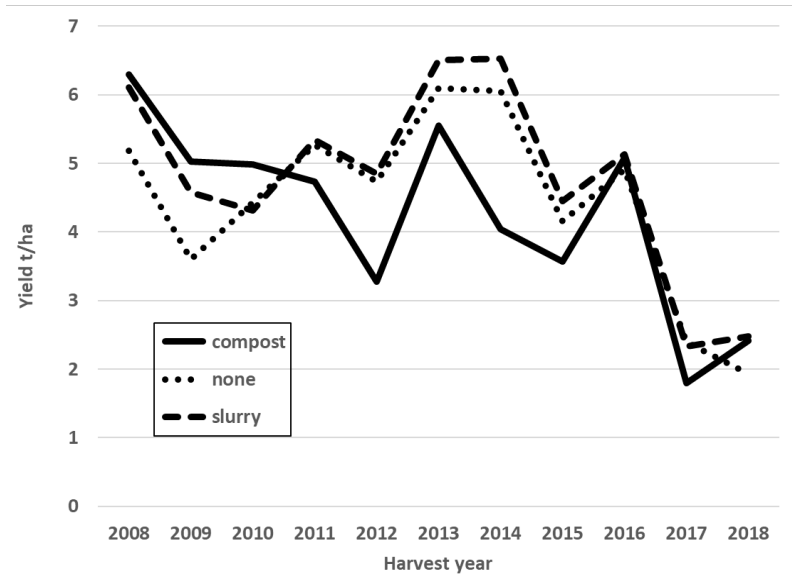

Figure 7. Effects of mean of levels of soil amendment treatments on yields of spring barley. Year ${ }^{*}$ amendment l.s.d $=0.389$.

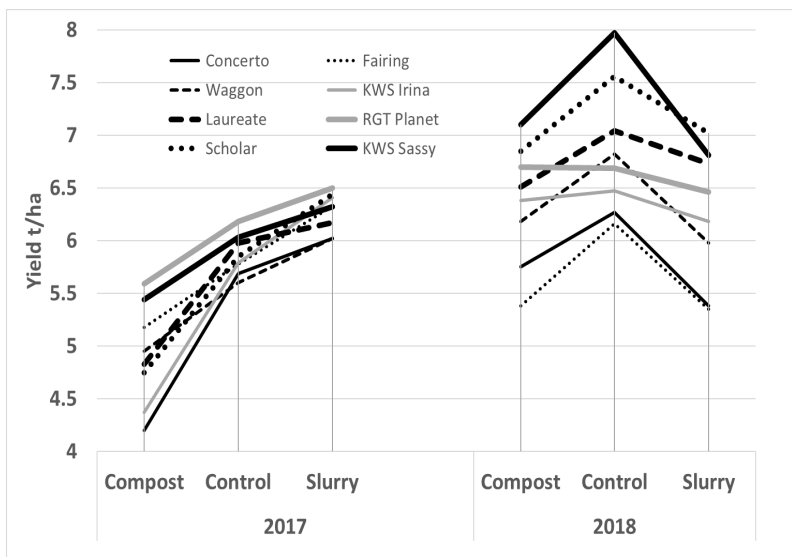

Figure 8. Effects of soil amendment and cultivar on yield in different years.

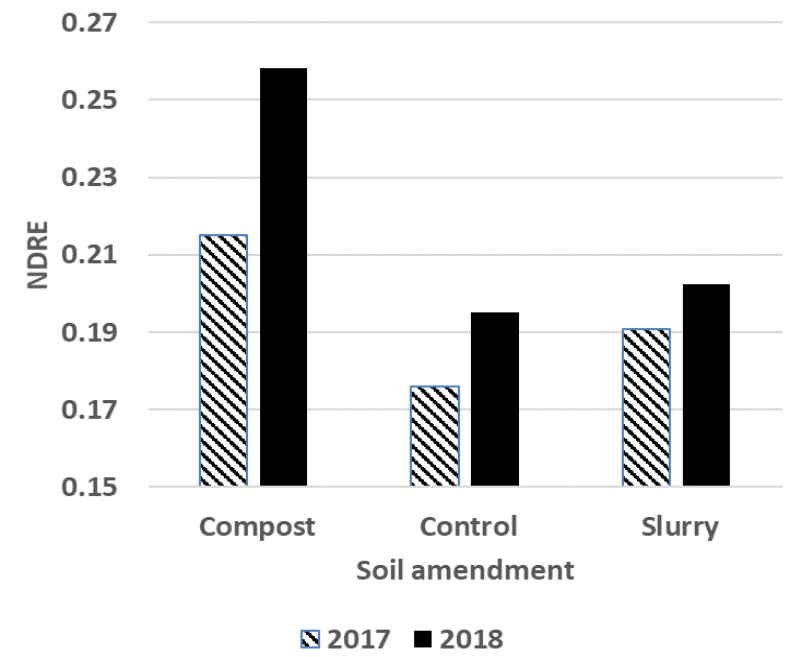

Figure 9. Effects soil amendment on the Normalised Difference Red Edge Index on spring barley measured on $13^{\text {th }}$ May 2017 and $18^{\text {th }}$ June 2018. Amendment ${ }^{\star}$ year 1.s.d. $=0.011$. 


\section{Discussion}

That previous crops and soil amendments can affect crop development and yield is not a novel finding. However, information about the relative effects and magnitude of different pre-crop treatments is valuable for novel crop development and agronomic treatment planning. Indeed, the sometimes marginal differences between the yield of new varieties is put into perspective by some of these data emphasising the importance of good agronomic management across crop cycles. This is particularly notable with the effects of restored rotation on winter wheat and winter barley where yields were $19 \%$ and $26 \%$ higher respectively compared with following continuous barley. This is likely to have been enhanced by direct drilling as ploughing might have accelerated losses from microbial activity and breakdown of nutrients in the roots and other organic matter. That this effect is species specific rather than an effect on cereals in general is clearly shown by the fact that the yield of winter wheat was not affected by the treatments. Furthermore, this demonstrates that the yield boost cannot be attributable to any nutritional effect of the immediately prior crop of faba beans as this would have been expected to affect at least both winter crops that were direct drilled at the same time in a similar way.

Nutrient explanations of continuous cropping effects have been investigated previously without clear mechanistic effects [12]. The mechanism are more likely to be predominantly microbial, possibly root-infecting pathogens including take-all. Roots were not assessed for take-all symptoms but the levels are very variable in previous studies of continuous spring barley [4] and there was no evidence of this disease above-ground on the wheat. Negative effects of monoculture soil have been attributable to the microbial components and these affected wheat and oats to a lesser extent than barley [13] which concurs with our findings. The apparent negative trend of rye which was only noted on subsequent winter wheat seems likely due to them both being nutrient-demanding crops and therefore reflecting nutrient depletion, particularly nitrogen.

Higher NDRE values are normally interpreted as indicating better crop health as it is correlated with leaf chlorophyll content and is a surrogate of $\mathrm{N} \%$ in the crop [14]. The values were all similar at early crop establishment in March but thereafter reflected better crop development for both winter wheat and winter barley. It is therefore perhaps surprising that the wheat did not benefit as much as the barley from this treatment, perhaps favouring a hypothesis that take-all was an important factor under continuous barley as residual inoculum might be expected to have a greater effect on wheat.

The very contrasting weather in the 2017 and 2018 seasons at the experimental site are likely to have had a big effect on the soil amendments, particularly as organic matter would be expected to affect water-holding capacity of the soil and thereby nutrient availability also. That compost amendments can reduce yield might appear surprising but changes in physical properties of the soil with re- 
spect to water and nutrients would affect responsiveness to abiotic stress levels and 2018 was much warmer and drier than normal and this was seen to a small degree in the data (Figure 7). The lower yields of the whole Low Pilmore field in 2017 and 2018 was attributed to the very late sowing date in 2017 and a combination of late sowing and the driest growing season for over 20 years in 2018 . We know from visual observations and NDRE measurements that the compost treatments enhanced plant development, as did slurry to a lesser extent. Nevertheless, there was no evidence consistent across the two years that any cultivar responded differentially to soil amendment treatment.

That the compost treatment was initially beneficial to yield and slurry to a lesser extent was expected as soil structure and nutrients would have shown improvements [15]. Subsequent the compost and control yields continued as might have been anticipated with the nutrient additions of the slurry most likely accounting for its beneficial effect. However, the recorded reduction of yield with the compost treatment seems counter-intuitive. No detailed monitoring of crop growth was carried out each year as the focus had been on effects on the soil, nevertheless it was noted in ad hoc aerial images and NDVI/NDRE monitoring that the developmental stage of the barley over the high level compost treatment could be up to a week ahead of other areas. As the trial design dictated that for both when a single variety was grown and for the plot trials, all plots had to be harvested at the same time, this would not be an optimum for either all treatment areas or all cultivars. Spring barley can be very prone to brackling losses of whole ears and this could have affected yield levels on treatments or cultivars differentially each year. Observations in 2016 noted high numbers of ears on the ground for the high compost treatment areas after combining but it was not possible to quantify these losses. Therefore, any conclusions about specific yield level effects of the treatments or the cultivars should be interpreted with caution.

These pre-crops form two clear groupings. In the more beneficial group, the pea and bean monocrop effects might be expected as direct nitrogen responses. However, that oats have a similar effect is less expected, but oats with peas or beans would therefore be expected to have a similarly positive effect. The differences between the groupings in yield response were around 30\%, 21\% and $10 \%$ for winter wheat, winter barley and spring barley respectively. Elite winter wheat cultivars are very nutrient demanding and responsive crops, as are winter barley and spring barley cultivars though likely to a lesser extent. Therefore, this ranking might be expected, especially as the spring barley was sown over 6 months later and as no cover crop was grown, more nutrient loss would be expected in this crop. Some difference may be attributable to residual nutrient differences left after the previous crops but given the similarity of their biomass yields in the previous trial to those expected (data not shown) this seems unlikely to explain the magnitude of these responses. More likely would be the known allelopathic effects of oats having a strong effect not only on other plant species but also on the microbial composition of the soil [16]. 


\section{Conclusion}

Crop sequence or rotation, the immediately preceding crop in particular, and soil organic amendments can have both detrimental and beneficial effects on subsequent crops. The trials reported here indicate a potential range of up to $30 \%$ of the yield, far greater than the benefits likely to be gained from changing cultivar for example. In particular, the utility of growing oat crops may be under-valued and ways of incorporating more legume crops should be considered. However, the value of soil amendments need to be carefully evaluated in the context of other soil health and resilience considerations.

\section{Acknowledgements}

We acknowledge the support the Scottish Government Rural and Environment Science and Analytical Services (RESAS) for funding this work under its strategic programme. We thank especially the Hutton farm staff for carrying out all the field operations and Roy Neilson for long-term maintenance of the Low Pilmore site.

\section{Conflicts of Interest}

The authors declare no conflicts of interest regarding the publication of this paper.

\section{References}

[1] Karlen, D.L., Varvel, G.E., Bullock, D.G. and Cruse, R.M. (1994) Crop Rotations for the 21st Century. Advances in Agronomy (USA), 53, 1-45. https://doi.org/10.1016/S0065-2113(08)60611-2

[2] Lawes, J.B. and Gilbert, J.H. (1894) Rotation of Crops. Journal of the Royal Agricultural Society of England, 55, 585-646.

[3] Dyke, G.V. and Slope, D.B. (1978) Effects of Previous Legume and Oat Crops on Grain Yield and Take-All in Spring Barley. Journal of Agricultural Science, 91, 443-451. https://doi.org/10.1017/S0021859600046542

[4] Hornby, D. and Hendry, D.R. (1986) Epidemics of Take-All during 16 Years of Continuous Spring Barley. Annals of Applied Biology, 108, 251-264. https://doi.org/10.1111/j.1744-7348.1986.tb07647.x

[5] Angus, J.F., Kirkegaard, J.A., Hunt, J.R., Ryan, M.H., Ohlander, L. and Peoples, M.B. (2015) Break Crops and Rotations for Wheat. Crop \& Pasture Science, 66, 523-552. https://doi.org/10.1071/CP14252

[6] Chalk, P.M. (1998) Dynamics of Biologically Fixed N in Legume-Cereal Rotations: A Review. Australian Journal of Agricultural Research, 49, 303-316. https://doi.org/10.1071/A97013

[7] Brooker, R.W., Bennett, A.E., Cong, W.-F., Daniell, T.J., George, T.S., Hallett, P.D., Hawes, C., Iannetta, P.P.M., Jones, H., Karley, A.J., Li, L., McKenzie, B.M., Pakeman, R.J., Paterson, E., Schoeb, C., Shen, J., Squire, G., Watson, C.A., Zhang, C., Zhang, F., Zhang, J. and White, P.J. (2015) Improving Intercropping: A Synthesis of Research in Agronomy, Plant Physiology and Ecology. New Phytologist, 206, 107-117. https://doi.org/10.1111/nph.13132 
[8] Soon, Y.K. and Arshad, M.A. (2004) Tillage, Crop Residue and Crop Sequence Effects on Nitrogen Availability in a Legume-Based Cropping System. Canadian Journal of Soil Science, 84, 421-430. https://doi.org/10.4141/S04-023

[9] Kimpinski, J., Gallant, C.E., Henry, R., Macleod, J.A., Sanderson, J.B. and Sturz, A.V. (2003) Effect of Compost and Manure Soil Amendments on Nematodes and on Yields of Potato and Barley: A 7-Year Study. Journal of Nematology, 35, 289-293.

[10] Courtney, R.G. and Mullen, G.J. (2008) Soil Quality and Barley Growth as Influenced by the Land Application of Two Compost Types. Bioresource Technology, 99, 2913-2918. https://doi.org/10.1016/j.biortech.2007.06.034

[11] Bailey, K.L. and Lazarovits, G. (2003) Suppressing Soil-Borne Diseases with Residue Management and Organic Amendments. Soil and Tillage Research, 72, 169-180. https://doi.org/10.1016/S0167-1987(03)00086-2

[12] Clark, R.V. and Mack, A.R. (1973) Effects of Growing Barley Continuously on Yields, Chemical Constituents, and Disease Prevalence. Canadian Journal of Plant Science, 54, 307-314. https://doi.org/10.4141/cjps74-048

[13] Olsson, S. and Gerhardson, B. (1992) Effects of Long-Term Barley Monoculture on Plant-Affecting Soil Microbiota. Plant and Soil, 143, 99-108.

https://doi.org/10.1007/BF00009134

[14] Barnes, E.M., Clarke, T.R. and Richards, S.E. (2000) Coincident Detection of Crop Water Stress, Nitrogen Status and Canopy Density Using Ground Based Multispectral Data. In: Robert, P.C., Rust, R.H. and Larson, W.E., Eds., Proceedings of the Fifth International Conference on Precision Agriculture, American Society of Agronomy, Madison, CD-ROM.

[15] Hopkins, D.W., Wheatley, R.E., Coakley, C.M., Daniell, T.J., Newton, A.C. and Neilson, R. (2016) Soil Carbon and Nitrogen and Barley Yield Responses to Repeated Additions of Compost and Slurry. Journal of Agricultural Science, 155, 141-155. https://doi.org/10.1017/S0021859616000307

[16] Manns, H.R., Maxwell, C.D. and Emery, N.R.J. (2009) Fungal Response from oat (Avena sativa) Plants and Surface Residue in Relation to Soil Aggregation and Organic Carbon. Journal of Plant Interactions, 4, 167-178. https://doi.org/10.1080/17429140902947010 